\title{
Urinary phosphorus rather than urinary calcium possibly increases renal stone formation in a sample of Asian Indian, male stone-formers
}

\author{
Shoma Berkemeyer ${ }^{1}$, Anupam Bhargava ${ }^{2}$ and Usha Bhargava ${ }^{1}$ \\ ${ }^{1}$ University of Delhi, Delhi, India \\ ${ }^{2}$ CDR Medical Centre and North Point Laboratories, New Delhi, India \\ (Received 12 January 2007 - Revised 25 April 2007 - Accepted 21 May 2007)
}

The contribution of dietary $\mathrm{Ca}$ and $\mathrm{P}$ in renal stone formation is debated. Thus, the main objective was to investigate if there were any differences in the dietary, serum and urine values of $\mathrm{Ca}$ and $\mathrm{P}$ in stone formers (SF) compared with healthy controls (HC). The secondary aim was to analyse if dietary, serum and urine $\mathrm{Ca}$ and $\mathrm{P}$ correlated. The study enrolled ten patients with renal stones admitted for stone removal and ten healthy controls. Their dietary macronutrients, $\mathrm{Ca}$ and $\mathrm{P}$ intakes were calculated from 2-d dietary records. On the second day of dietary record 24-h urine was collected and on the third day morning a $5 \mathrm{ml}$ blood sample was collected. Biochemical analyses were conducted for serum and urine $\mathrm{Ca}$, $\mathrm{P}$ and uric acid with qualitative renal stone analysis. All the dietary intakes and urine $\mathrm{P}$ were significantly higher $(P<0 \cdot 05)$ in $\mathrm{SF}$ than in $\mathrm{HC}$. Correlation results showed that in SF dietary Ca correlated to serum and urine Ca. No such correlations were seen for P. Additionally, in SF urine Ca correlated to dietary proteins and fats but not to carbohydrates. None of the biochemical values lay outside the normal range of values. The study suggests urine $\mathrm{P}$ rather than urine $\mathrm{Ca}$ to be probably at work in the formation of renal stones. Limitation of protein intake with normal Ca intakes could provide a suitable measure to avoid renal stone formation.

Ca: P: Renal stones: Hyperparathyroidism: Absorptive hypercalciuria

Various epidemiological factors such as nutrition, age, sex, socio-economic group, climate, disease conditions, crystallization dynamics and heredity have been mentioned in the aetiology of renal stones. Nutritionally, the contribution of dietary $\mathrm{Ca}$ and $\mathrm{P}$ in renal stone formation is still debated. Both $\mathrm{Ca}$ and $\mathrm{P}$ are usually found as renal stone components. Conventionally, dietary $\mathrm{Ca}$ limitation used to be recommended to prevent recurrent episodes of renal stones, but later studies have shown that dietary $\mathrm{Ca}$ is related to lower risk of $\mathrm{Ca}$ oxalate renal stone formation. ${ }^{1}$ This is so because $\mathrm{Ca}$ binds dietary oxalates in the intestine, thereby reducing the quantity of oxalates absorbed and thus reducing stone formation risk, as far as oxalate intake is substantial.

The contribution of dietary $\mathrm{P}$ remains unclear. $\mathrm{P}$ therapy to avoid stone formation has been reported to not reduce $\mathrm{Ca}$ oxalate crystallization in urine. ${ }^{2}$ In addition, studies have reported urine $\mathrm{P}$ to affect ${ }^{3-6}$ as well as to not affect ${ }^{7}$ the formation of renal stones. Thus, nutritionally the present study identified $\mathrm{Ca}$ and $\mathrm{P}$ as the key dietary components, which are still debated, either directly as in their dietary intakes or indirectly through their metabolic processes, in the aetiology of renal stone formation.

\section{Materials and methods}

\section{Subjects}

The present study was carried out in ten stone formers (SF) and ten healthy controls (HC). The SF had been admitted for renal stone(s) removal at the CDR Medical Centre and were asked to join the study on a voluntary basis. Male SF in their second to fifth decade of life were selected, since a male sex bias in middle-age has been reported as a renal stone risk ${ }^{1,8}$. The age and sex matched HC were recruited, again on a voluntarily basis, contacted by local advertisements, from among the employees of the medical centre and the University of Delhi on condition that they never had any episodes of renal stones or any family history of stone formation. The HC thereafter underwent a clinical examination by the attending physician at the medical centre and were diagnosed to have no illnesses, chronic or infectious. All subjects provided written informed consents and the study was approved by the university and the medical centre.

\section{Study design}

A questionnaire cum interview schedule was administered to recruit the SF for the study and all their data were collected prior to removal of their renal stones. The $\mathrm{HC}$ were recruited using a slightly modified version of the schedule. Compliance was discussed and confirmed verbally with all participants, with the provision of free dietary advice on the successful completion of the dietary, serum and urine data gathering. Each study participant at first collected a 2-d dietary food record. In the case of SF, most of them were on home-food diet, even as inpatients of the centre. The second day of the 
dietary food record corresponded to the 24-h urinary sample collection. On the morning of the third day, the dietary records and urine samples were delivered to the North Point Laboratories, when also a fasting blood sample was drawn by trained laboratory personnel. After the dietary, serum and urine data gathering were completed, the renal stones, which were removed from the SF, were qualitatively analysed for their contents. All biochemical analyses were carried out at the North Point Laboratories.

\section{Dietary intake data}

A 2-d dietary record was administered with verbal pre-instructions on how to record food intake using measuring scales and a set of standardized bowls, glasses and spoons, ${ }^{9}$ all recorded in a booklet provided to each subject. Cooked food intakes were converted to corresponding raw portions and the mean intakes of energy, carbohydrate, fats, protein, $\mathrm{Ca}$ and $\mathrm{P}$ were calculated using the food tables of Nutritive Value of Indian Foods. ${ }^{10}$

\section{Urinary data}

Urine samples $(24 \mathrm{~h})$ of HC were collected in eleven chemically clean, plastic containers, which were provided to the participants. The 24-h urine samples of the SF, who at the time of the study were inpatients of the centre, were collected in urobags, which were pyrogen-free, ethylene oxide (ETO) gas sterilized, fitted with a long tube with a non-return valve. All participants were asked to discard the first morning urine sample, note the time and collect every sample thereafter for the next $24 \mathrm{~h}$ until the morning of the following day. All (Mean values and standard deviations) urine samples were analyzed immediately on the day they were delivered to the laboratory.

\section{Serum data}

A fasting blood sample was drawn by a venipuncture of the antecubital vein using $5 \mathrm{ml}$ disposable plastic syringes (Careject, Carewell Mediproducts Ltd, New Delhi, India sterile, non-toxic, pyrogen free, ETO sterilized and contamination free) with single-use needles (Luer, Iscon Surgical Ltd, Jodhpur, India $0.80 \times 38 \mathrm{~mm}$, sterile, non-toxic and non-pyrogenic). The $5 \mathrm{ml}$ fasting blood aliquot was stored at room temperature for $1 \mathrm{~h}$ in a sterile, acid-washed test tube for clot formation. It was then centrifuged for $10 \mathrm{~min}$ at $2000 \mathrm{rpm}$. The serum obtained was analysed immediately.

\section{Biochemical analyses}

Serum and urine $\mathrm{Ca}, \mathrm{P}$ and uric acid were measured colorimetrically using the EDTA method, ${ }^{11}$ the molybdate method $^{12}$ and the tungsten blue method, ${ }^{13}$ respectively. Urine creatinine was measured using the picrate method. ${ }^{14}$ Renal stones were qualitatively (chemically) analyzed for the presence of $\mathrm{Ca}$, phosphate, oxalate, carbonate, urate, $\mathrm{Mg}$ and cystine. ${ }^{15-17}$

\section{Statistics}

Statistical analysis was carried out using means and standard deviations. Variables that were not normally distributed were log-transformed. Comparisons between the two groups (SF, HC) were carried out by the $t$ test. To find out relationships

Table 1. Data characteristics of the stone formers (SF) and healthy control $(\mathrm{HC})$ groupst

\begin{tabular}{|c|c|c|c|c|c|}
\hline & \multicolumn{2}{|c|}{ SF $(n 10)$} & \multicolumn{2}{|c|}{$\mathrm{HC}(n 10)$} & \multirow[b]{2}{*}{ Normal range } \\
\hline & Mean & SD & Mean & SD & \\
\hline \multicolumn{6}{|l|}{ Dietary intakes } \\
\hline Energy (kJ/d) & $14096^{\star}$ & 3759 & 8728 & 1966 & - \\
\hline Carbohydrates (g/d) & $448 \cdot 1^{*}$ & 128.9 & 304.6 & $77 \cdot 8$ & - \\
\hline Fats $(g / d)$ & $110 \cdot 1^{*}$ & 34.5 & $61 \cdot 2$ & $24 \cdot 3$ & - \\
\hline Protein (g/d) & $111 \cdot 1^{*}$ & $41 \cdot 0$ & 67.9 & $16 \cdot 1$ & - \\
\hline $\mathrm{Ca}(\mathrm{g} / \mathrm{d})$ & $1 \cdot 38^{*}$ & 0.60 & 0.75 & 0.29 & - \\
\hline$P(g / d)$ & $2 \cdot 67^{*}$ & 0.83 & 1.79 & 0.61 & - \\
\hline \multicolumn{6}{|l|}{ Serum parameters } \\
\hline $\mathrm{Ca}(\mathrm{mg} / \mathrm{dl})$ & $9 \cdot 2$ & $1 \cdot 2$ & $9 \cdot 0$ & 0.9 & $8 \cdot 5-10 \cdot 5$ \\
\hline$P(\mathrm{mg} / \mathrm{dl})$ & 3.5 & 0.9 & $3 \cdot 4$ & 0.7 & $2 \cdot 5-4 \cdot 5$ \\
\hline Uric acid (mg/dl) & $5 \cdot 5$ & 1.4 & $5 \cdot 1$ & $1 \cdot 2$ & $3 \cdot 0-8 \cdot 2$ \\
\hline \multicolumn{6}{|l|}{ Urine parameters } \\
\hline $\mathrm{Ca}(\mathrm{mg} / \mathrm{d})$ & $149 \cdot 3$ & $32 \cdot 2$ & $145 \cdot 6$ & $30 \cdot 1$ & $100-300$ \\
\hline$P(\mathrm{mg} / \mathrm{d})$ & $617 \cdot 7^{\star}$ & 194.6 & 358.5 & $119 \cdot 5$ & $400-1300$ \\
\hline Uric acid (mg/d) & $537 \cdot 3$ & $315 \cdot 0$ & $402 \cdot 8$ & 131.4 & $250-750$ \\
\hline Creatinine $(\mathrm{g} / \mathrm{d})$ & 1.6 & 0.3 & 1.6 & 0.2 & $0.8-2.4$ \\
\hline Volume $(\mathrm{ml} / \mathrm{d})$ & 1457 & $421 \cdot 2$ & 1650 & 374.9 & - \\
\hline \multicolumn{6}{|c|}{ Qualitative stone data, number of SF with the following renal stone components } \\
\hline $\mathrm{Ca}$ & 10 & & & - & - \\
\hline Oxalate & 10 & & & - & - \\
\hline Phosphate & 7 & & & - & - \\
\hline Uric acid & 2 & & & - & - \\
\hline
\end{tabular}

Mean values were significantly different from the $\mathrm{HC}$ group; ${ }^{\star} P<0.05$ using $t$ test of difference. $\dagger$ For details of subjects and procedures, see Materials and methods. 
among the dietary intakes, serum levels and urinary excretions of the variables, Pearson's correlations were run. Both the test of difference and the correlations were considered to be statistically significant at $P<0 \cdot 05$.

\section{Results}

All the mean dietary intakes reported in Table 1 were significantly higher $(P<0.05)$ in SF compared with HC. In general, SF had a higher food intake, as shown by their daily total energy $(\mathrm{kJ} / \mathrm{d})$ intake values. None of the serum or urine variables was significantly different between the two groups, except urine $\mathrm{P}(P<0.05)$, which was significantly higher in $\mathrm{SF}$. The stone composition results showed that all ten SF had $\mathrm{Ca}$ and oxalate in their renal stones. In addition to the $\mathrm{Ca}$ and oxalate, seven had phosphate and two had urate in their renal stones.

When diet, serum and urine values for $\mathrm{Ca}, \mathrm{P}$ and uric acid (dietary uric acid intake indexed with dietary protein) were correlated (Table 2), neither dietary $\mathrm{P}$ nor uric acid showed any relation to their serum or urine values. In SF, dietary $\mathrm{Ca}$ correlated not only to serum but also to urine $\mathrm{Ca}$, whereas in $\mathrm{HC}$ no such correlations were observed. In addition, SF exhibited the often reported dietary proteinrelated calciuria, whereby the SF had a significantly higher protein intake compared with $\mathrm{HC}$. Urine $\mathrm{P}$ was not significantly, though positively, related to dietary protein and $\mathrm{P}$ in both groups.

In $\mathrm{HC}$, neither urine $\mathrm{Ca}$ nor urine $\mathrm{P}$ correlated to any of the dietary macronutrient intakes. Likewise, in SF urine $\mathrm{P}$ showed no correlation to dietary macronutrient intakes. Only urine $\mathrm{Ca}$ in SF correlated positively to total energy intake (0.66, $P<0.05)$, dietary protein $(0.72, P<0.05)$, fats $(0.80$, $P<0.05)$ and $\mathrm{P}(0.69, P<0.05)$ intakes. However urine $\mathrm{Ca}$ in SF showed no correlation to dietary carbohydrate intakes.

\section{Discussion}

In the present study, urine $\mathrm{P}$ was significantly higher in SF compared with $\mathrm{HC}$ and it did not correlate significantly to any dietary macronutrient intakes in both groups. In contrast, urine $\mathrm{Ca}$ correlated significantly to dietary intakes of energy, protein and fats (not carbohydrates) in SF only. Finally, only dietary $\mathrm{Ca}$ correlated significantly to serum and urine $\mathrm{Ca}$ in SF. Thus, a dietary contribution, defined by energy, protein and fats, to the urine $\mathrm{Ca}$ excretion in SF could be possible. A dietary contribution to urine $\mathrm{Ca}$ excretion in SF has been reported in literature. ${ }^{18,19}$ In contrast to the present study, these studies have also reported carbohydrates. Elevated urine $\mathrm{P}$ in $\mathrm{SF}$, with urine $\mathrm{P}$ demonstrating no significant correlations to any of the dietary intakes, probably hints at $\mathrm{P}$ metabolism rather than its intake to be in play in renal stone formation. Studies have reported an altered phosphate handling in SF secondary to parathyroid hormone (PTH) disorders $^{6,20}$ as well as primary changes in renal tubulus ${ }^{4,5}$ leading to phosphate waste.

Of note was that none of the biochemical parameters in both groups in the present study lay outside the normal range of values. Simultaneously, dietary intakes in SF were clearly higher than in HC. Thus, the occurrence of renal stones in one group and none in the other could probably be influenced

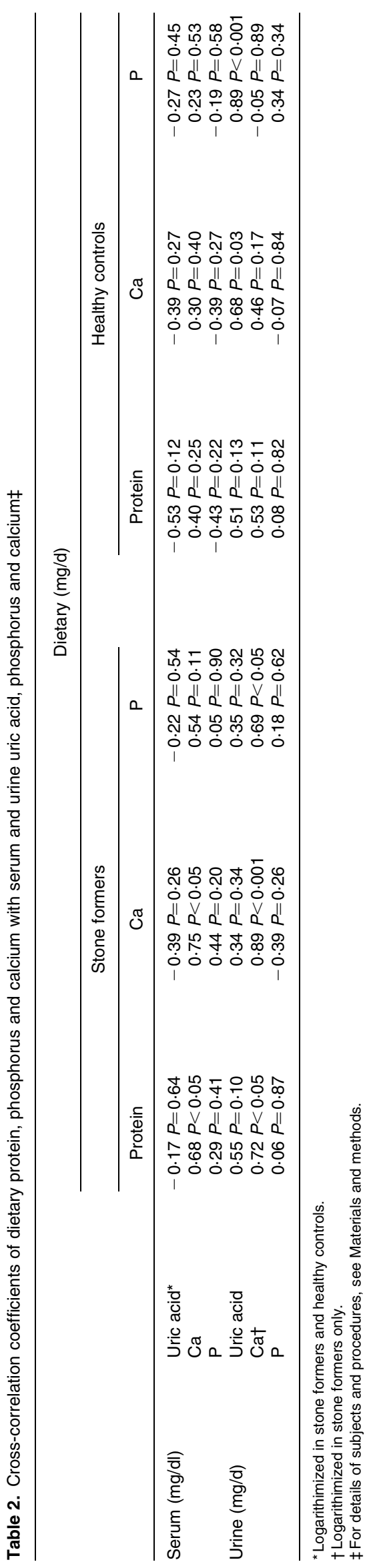


by hyperphagy. Renal stone formation has been associated with affluence. ${ }^{19}$ With affluence, apart from quantitative increases in food consumption, a tendency to replace carbohydrates with protein and fats as a source of energy is observed. $^{21}$ There is the added observation that SF tend to be obese, ${ }^{22,23}$ reflecting prolonged increased food consumption. In the current study, the SF, apart from higher food consumption, in terms of food groups, consumed more meats, milk and milk products. In fact, the HC group was principally vegetarian in food habits. Increased dietary protein consumption leading to urine $\mathrm{Ca}$ losses in $\mathrm{SF}$ is well documented, ${ }^{24}$ although not only limited to $\mathrm{SF}^{25}$ Thus, the loss of $\mathrm{Ca}$ in the urine in SF could be due to high protein consumption.

Urine Ca loss could be also due to idiopathic hypercalciuria. ${ }^{26}$ However, the observed normocalciuria in SF probably suggests an absorptive hypercalciuria, which is accompanied by mild to moderate phosphate loss but rarely with renal hypercalciuria. ${ }^{27}$ In patients with absorptive hypercalciuria, bone disease rarely sets ${ }^{27}$ in possibly because of the higher Ca absorption, which would protect bone resorption. Ca limitation in such patients could then probably affect their bone health. Thus, the present study supports the thesis of not limiting $\mathrm{Ca}$ intake in SF, suggested by other studies as well, ${ }^{1,8}$ since apart from the known protective function of binding oxalates in the gut, $\mathrm{Ca}$ intake in SF with absorptive hypercalciuria would also exert a bone-protective function.

In addition to the afore-mentioned arguments, urine Ca may not be as critical as urine $\mathrm{P}$ in starting the process of stone formation. $\mathrm{P}$ excretion per se has been related to dietary protein intake. ${ }^{28} \mathrm{~A}$ role for dietary protein in increasing the risk of renal stone formation has often been mentioned. ${ }^{19,29}$ Concepts of 'proportional' rather than the 'raw' concentrations ${ }^{30}$ of, for example, $\mathrm{P}$ and/or the amount of $\mathrm{P}$ excreted for any given serum $\mathrm{Ca}^{6}$ have also been mentioned to distinguish stone formation. It appears, however, that urine $\mathrm{P}$ rather than dietary $\mathrm{P}^{2}$ is the parameter to reconsider.

Studies have shown ${ }^{4-6,20,31}$ that Ca-containing renal stones are related to impaired $\mathrm{P}$ excretion. Schwille and colleagues ${ }^{31}$ reported that changes in calcium phosphate and calcium oxalate renal stones' (the predominant stone composition profile of the SF in the present study) supersaturation in urine was unrelated to urine $\mathrm{Ca}$ excretion. Calcium phosphate has been reported to form the renal stone nidus $s^{32}$ and in animal studies Bushinsky and colleagues ${ }^{33}$ reported that a decrease in urine $\mathrm{P}$, secondary to a decrease in dietary $\mathrm{P}$, led to a decrease in the urine supersaturation of calcium phosphate. Thus, although $\mathrm{Ca}$ forms an important component of renal stones, the trigger that conduces the stone precipitation could lie in urine P. This could possibly also explain why dietary protein restriction is often recommended for $\mathrm{SF}{ }^{8,19}$ Urine $\mathrm{P}$, apart from reflecting dietary $\mathrm{P}$ (as shown in animal studies ${ }^{33}$ ), possibly also reflects the proton load of the dietary proteins excreted in the urine as phosphates.

The other mechanisms, in addition to dietary proteins, whereby urine $\mathrm{P}$ could contribute to stone formation could be due to the action of $\mathrm{PTH}^{6,20}$ and/or changes in the renal tubular structure. ${ }^{4,5}$ Regarding the latter, a contribution of lipids through the alteration in the phospholipid structure of intestinal $^{26}$ and renal tubular cells ${ }^{31}$ has been proposed to lead to stone formation by increasing $\mathrm{Ca}$ absorption in the gut $^{26}$ and phosphate loss (independent of PTH) in the renal tubulus, ${ }^{31}$ respectively. The present study's SF had a high consumption of fats. If high or altered fat consumption, or even higher food intake per se (ultimately leading to obesity ${ }^{22,23}$ ), can be related to changes in membrane phospholipid structure affecting $\mathrm{Ca}$ and $\mathrm{P}$ absorptions and excretions (secondary to metabolic abnormalities or even in their absence) it warrants further studies. In addition to the dietary food habits and the higher urine $\mathrm{P}$ excretion by the present study's SF compared with $\mathrm{HC}$, stone formation would be exacerbated by any existing metabolic abnormalities and/or genetic proclivity; the measurements of which lay outside the scope of the current study. What is known is that, geographically, North India is counted as a region prone to stone formation, ${ }^{34}$ with Delhi falling in the stone-forming belt of North India.

The present study was planned to investigate $\mathrm{Ca}$ and $\mathrm{P}$ in SF. Given the afore-mentioned arguments, post priori, this study would have benefited vastly from additional measurements of classical urine parameters, such as $\mathrm{pH}$, oxalate, sulphate and citrate and also serum PTH and vitamin D. This study remains limited in the lack of such measurements. Further, the study sample size of ten in each group would limit extrapolations for the general population.

Taken together, the present study found higher food consumption and higher phosphate excretion in SF. The study suggests urine $\mathrm{P}$ rather than urine $\mathrm{Ca}$ to be probably at work in the formation of renal stones. Limitation of dietary protein with normal $\mathrm{Ca}$ intakes could provide a suitable measure to avoid renal stone formation for the study's SF.

\section{Acknowledgements}

The laboratory analyses were supported by the North Point Laboratories as a grant. The authors report no conflict of interest, financial or otherwise.

\section{References}

1. Curhan GC, Willett WC, Rimm EB \& Stampf MJ (1993) A prospective study of dietary calcium and other nutrients and the risk of symptomatic kidney stones. N Engl J Med 328, 833-838.

2. Ettinger B (1976) Recurrent nephrolithiasis: natural history and effect of phosphate therapy. A double-blind controlled study. Am J Med 61, 200-206.

3. Schwille PO, Schmiedl A \& Manoharan M (2004) Is calcium oxalate nucleation in postprandial urine of males with idiopathic recurrent calcium urolithiasis related to calcium phosphate nucleation and the intensity of stone formation? Studies allowing insight into a possible role of urinary free citrate and protein. Clin Chem Lab Med 42, 283-293.

4. Wikstrom B, Backman U, Danielson BG, Fellstrom B, Hellsing K, Johansson G \& Ljunghall S (1981) Phosphate metabolism in renal stone formers. (I): Indices of phosphate handling in calcium stone patients and healthy subjects. Scand J Urol Nephrol Suppl 61, 1-18.

5. Wikstrom B, Backman U, Danielson BG, Fellstrom B, Johansson G Ljunghall S \& Wide L (1981) Phosphate metabolism in renal stone formers. (II): Relation to renal tubular functions and calcium metabolism. Scand J Urol Nephrol Suppl 61, $1-26$.

6. Williams CP, Child DF, Hudson PR, Soysa LD, Davies GK, Davies MG \& De Bolla AR (1996) Inappropriate phosphate excretion in idiopathic hypercalciuria: the key to a common cause and future treatment? J Clin Pathol 49, 881-888. 
7. Muezzinoglu T, Gumus B, Sener E, Ari Z \& Buyuksu C (2002) The diagnostic value of the phosphate levels in serum and 24hour urine samples in patients with recurrent renal stone disease. Scand J Urol Nephrol 36, 368-372.

8. Taylor EN \& Curhan GC (2006) Diet and fluid prescription in stone disease. Kidney Int 70, 835-839.

9. Raina UK, Kashyap S \& Narula V (1984) Basic Food Preparation: A Complete Manual. Hydrabodi: Orient Longman Limited.

10. Gopalan C, Ramashastri BB, Balasubramanium SC, Rao N, Deosthale YS \& Pant KC (1989) Nutritive Value of Indian Foods, Hydrabad: National Institute of Nutrition and Indian Council of Medical Research.

11. Trinder P (1960) Colorimetric microdetermination of calcium in serum. Analyst 85, 889-894.

12. Gomori M (1942) Modification of colorimetric phosphorus determination for use with photoelectric colorimeter. $J \mathrm{Lab}$ Clin Med 21, 955-960.

13. Folin O \& Denis W (1913) A new (colorimetric) method for the determination of uric acid in blood. $J$ Biol Chem xiii, 469-475.

14. Bonses RW \& Taussky HH (1945) On the colorimetric determination of creatinine by the Jaffe reaction. J Biol Chem 158, 581-591.

15. Reiner M, Cheung HL \& Thomas JL (1970) Calculi. In Standard Methods of Clinical Chemistry, pp. 193-205 [RP MacDonald, editor]. New York: Academic Press.

16. McIntosh JF \& Salter RW (1942) The qualitative examination of urinary calculi. J Clin Invest 21, 751-754.

17. Hodgkinson A (1971) A combined qualitative and quantitative procedure for the chemical analysis of urinary calculi. J Clin Pathol 24, 147-151.

18. Burtis WJ, Gay L, Insogna KL, Ellison A \& Broadus AE (1994) Dietary hypercalciuria in patients with calcium oxalate kidney stones. Am J Clin Nutr 60, 424-429.

19. Borghi L, Meschi T, Maggiore U \& Prati B (2006) Dietary therapy in idiopathic nephrolithiasis. Nutr Rev 64, 301-312.

20. Taguchi K, Kuwahara M, Kambe K, Loritani N, Saitoh T, Shirai S, Orikasa S, Mizunashi K \& Furukawa Y (1992) The pathogenesis of hypercalciuria from the aspect of the response to human parathyroid hormone in Ca containing stone formers. Nippon Hinyokika Gakkai Zasshi 83, 1101-1109.

21. Regmi A, Deepak MS, Seale JLJ \& Bernstein J (2001) CrossCountry Analysis of Food Consumption Patterns, Washington, DC: Economic Research Service, USDA.
22. Hassapidou MN, Paraskevopoulous STH, Karakoitsides PA, Petridis D \& Fotiadou E (1999) Dietary habits of patients with renal stone disease in Greece. J Hum Nutr Diet 12, 47-51.

23. Taylor EN, Stampfer MJ \& Curhan GC (2005) Obesity, weight gain, and the risk of kidney stones. JAMA 293, 455-462.

24. Giannini S, Nobile M, Sartori L, Dalle Carbonare L, Ciuffreda M, Corro P, D'Angelo A, Calo L \& Crepaldi G (1999) Acute effects of moderate dietary protein restriction in patients with idiopathic hypercalciuria and calcium nephrolithiasis. Am J Clin Nutr 69, 267-271.

25. Cardinale M, Leiper J, Farajian P \& Heer M (2007) Whole-body vibration can reduce calciuria induced by high protein intakes and may counteract bone resorption: A preliminary study. J Sports Sci 25, 111-119.

26. Duncombe VM, Watts RW \& Peters TJ (1984) Studies on intestinal calcium absorption in patients with idiopathic hypercalciuria. $Q J$ Med 53, 69-79.

27. Giannini S, Nobile M, Sella S \& Dalle Carbonare L (2005) Bone disease in primary hypercalciuria. Crit Rev Clin Lab Sci 42, 229-248.

28. Williams PS, Stevens ME, Fass G, Irons L \& Bone JM (1991) Failure of dietary protein and phosphate restriction to retard the rate of progression of chronic renal failure: a prospective, randomized, controlled trial. $Q J$ Med 81, 837-855.

29. Robertson WG, Peacock M \& Hodgkinson A (1979) Dietary changes and the incidence of urinary calculi in the UK between 1958 and 1976. J Chronic Dis 32, 469-476.

30. Rodgers AL, Barbour LJ, Pougnet BM, Lombard CJ \& Ryall RL (1995) Re-evaluation of the "week-end effect" data: possible role of urinary copper and phosphorus in the pathogenesis of renal calculi. J Trace Elem Med Biol 9, 150-155.

31. Schwille PO, Herrmann U, Schmiedl A, Kissler H, Wipplinger J \& Manoharan M (1997) Urinary phosphate excretion in the pathophysiology of idiopathic recurrent calcium urolithiasis: hormonal interactions and lipid metabolism. Urol Res 25, $417-426$

32. Vasin SL, Rosanova IB \& Sevastianov VI (1998) The role of proteins in the nucleation and formation of calcium-containing deposits on biomaterial surfaces. J Biomed Mater Res 39, 491-497.

33. Bushinsky DA, Parker WR \& Asplin JR (2000) Calcium phosphate supersaturation regulates stone formation in genetic hypercalciuric stone-forming rats. Kidney Int 57, 550-560.

34. Walsh PC, Retik AB \& Stamey TA (1992) Campbell's Urology. Philadelphia: W.B.: Saunders Company. 